Western University

Scholarship@Western

$9-24-2018$

\title{
Surprising Antibacterial Activity and Selectivity of Hydrophilic Polyphosphoniums Featuring Sugar and Hydroxy Substituents.
}

Tyler J Cuthbert

Benjamin Hisey

Tristan D Harrison

John F Trant

Elizabeth R Gillies

See next page for additional authors

Follow this and additional works at: https://ir.lib.uwo.ca/chempub

Part of the Chemistry Commons

\section{Citation of this paper:}

Cuthbert, Tyler J; Hisey, Benjamin; Harrison, Tristan D; Trant, John F; Gillies, Elizabeth R; and Ragogna, Paul J, "Surprising Antibacterial Activity and Selectivity of Hydrophilic Polyphosphoniums Featuring Sugar and Hydroxy Substituents." (2018). Chemistry Publications. 131.

https://ir.lib.uwo.ca/chempub/131 
Authors

Tyler J Cuthbert, Benjamin Hisey, Tristan D Harrison, John F Trant, Elizabeth R Gillies, and Paul J Ragogna 


\title{
Surprising Antibacterial Activity and Selectivity of Hydrophilic Polyphosphoniums Featuring Sugar and Hydroxyl Substituents
}

\author{
Tyler J. Cuthbert, ${ }^{[a]}$ Benjamin Hisey, ${ }^{[a]}$ Tristan D. Harrison, ${ }^{[a]}$ John F. Trant, ${ }^{[a]}$, Elizabeth R. Gillies, ${ }^{*[a] b]}$
} and Paul J. Ragogna*[a]

Dedication ((optional))

\begin{abstract}
There is currently an urgent need for the development of new antibacterial agents to combat the spread of antibiotic resistant bacteria. We explored the synthesis and antibacterial activities of novel, sugar-functionalized phosphonium polymers. While these compounds exhibited antibacterial activity, we unexpectedly found that control polymer poly(tris(hydroxypropyl)vinylbenzylphosphonium chloride) had very high activity against both Gram-negative Escherichia coli and Grampositive Staphylococcus aureus and very low haemolytic activity against red blood cells. These results challenge the conventional wisdom in the field that lipophilic alkyl substituents are required for high antibacterial activity and opens prospects for new classes of antibacterial polymers.
\end{abstract}

The increasing emergence of antibiotic-resistant and persistent bacteria is a major challenge in public health. The development of new safe and effective strategies that are easy and economical to implement to combat the spread of infection is increasingly urgent. Natural antimicrobial peptides are the first line of defense for organisms. ${ }^{[1]}$ Synthetic antibacterial macromolecules inspired by these peptides have been investigated as potential biocides as they are easily synthesized and are stable towards enzymatic degradation. ${ }^{[2-4]}$ A common feature of synthetic antibacterial polymers is their amphiphilic structure. Sufficient cationic charge is required for adhesion of the polymer to the bacterial cell surface and hydrophobic groups are generally required for insertion into and disruption of the bacterial membrane, although other mechanisms have also been proposed. ${ }^{[1]}$ Thus far, a wide range of macromolecular structures including polymethacrylates, ${ }^{[5,6]}$ polyamides, ${ }^{[7]}$ polyvinylpyridines, ${ }^{[8]}$ and polynorbornenes ${ }^{[9,10]}$ have been investigated. Different approaches for achieving amphiphilicity have been studied, including the copolymerization of hydrophobic and cationic monomers, the use of facially amphiphilic monomers, and the use of monomers with hydrophobic groups directly attached to the cationic centre. ${ }^{[11]}$ Detailed structure-property studies have shown that achieving high antibacterial activity with low mammalian cell toxicity, indicated by the ability of the molecules to lyse red blood cells (hemolysis), involves a delicate balance of cationic charge and hydrophobicity, with careful tuning required for each system..$^{[6,8-10,12-15]}$ In general, higher hydrophobicity leads to higher antibacterial activity but also increased hemolysis.

While polyammoniums have been extensively studied, there has been much less research on polyphosphoniums. Kanazawa et al. showed that polymeric phosphonium salts exhibited higher antibacterial activity compared to analogous polymeric ammonium salts. ${ }^{[16]}$ The incorporation of polyphosphoniums into cross-linked networks has also provided effective antibacterial surfaces. ${ }^{[17,18]}$ However, the scope of investigated structures has been limited to alkyl or aryl derivatives (Figure 1). ${ }^{[16,19-23]}$ In particular, strategies that aim to "bait and kill" have not been employed, despite significant opportunities to use such an approach in designing new and effective antimicrobial agents.

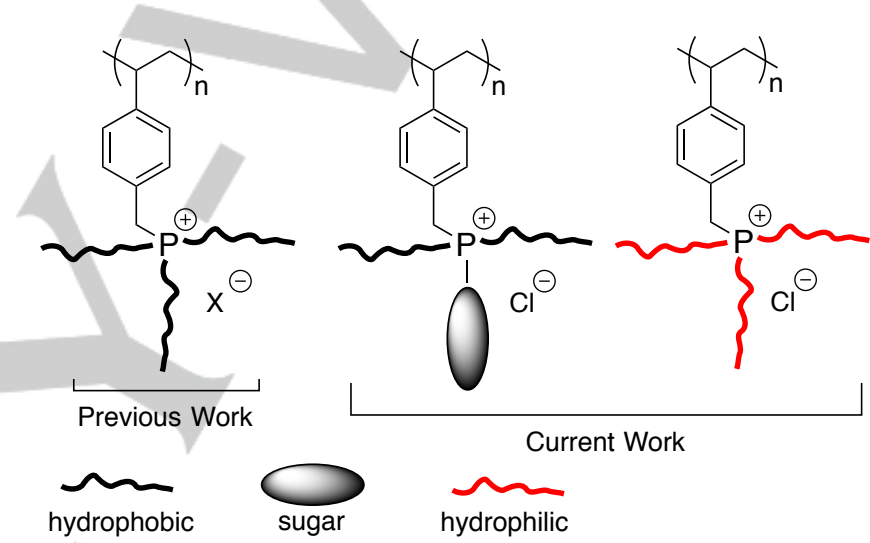

Figure 1. Benchmark polyphosphonium biocides reported by Kanazawa et al. emphasizing structure-property relationships of hydrophobic functional groups as compared to the hydrophilic materials in the current work ${ }^{[16,19-22]}$

It is known that Escherichia coli (E. coli) express mannose-binding proteins on their hairlike appendages called pili, enabling them to bind to glycoconjugates on mammalian cell surfaces. ${ }^{[24]}$ On this basis, we proposed that an amphiphilic polyphosphonium with pendant mannose moieties would exhibit increased binding to and killing of $E$. coli. In this context, starting from $\mathrm{PH}_{3}(\mathrm{~g})$, we report the synthesis of unique carbohydrate-containing phosphonium monomers and polymers with either mannoside or glucoside (control) substituents and hydrophobic hexyl chains as well as a tris(hydroxypropyl)phosphinum-functionalized control polymer. Surprisingly, we find that this control polymer, lacking any hydrophobic alkyl chains, exhibits very high antibacterial activity and very low hemolytic activity. Thus, for the first time, we have been able to probe the impact of these hydrophilic substituents on antibacterial activity and provide a direct comparison to the established poly(trialkylphosphonium) biocides.

The phosphonium monomers were prepared directly from $\mathrm{PH}_{3}(\mathrm{~g})$ (Figure 2). Dilute solutions $(<3.5 \mathrm{mM}$ ) of peracetylated $\alpha-$ allyl mannoside (Ac-Man) or the glucoside analogue (Ac-Glu) and $1 \mathrm{~mol} \%$ of initiator (w.r.t. alkene) were loaded into a pressure reactor. Once charged with $\mathrm{PH}_{3}$ at 80 psi, the apparatus was heated to $45{ }^{\circ} \mathrm{C}$. This low radical flux, excess $\mathrm{PH}_{3}$, and mild 
heating was critical in preparing $1^{\circ}$ phosphine selectively, with only trace amounts of $2^{\circ}$ phosphine, as detected by ${ }^{31} \mathrm{P}$ NMR spectroscopy. The $1^{\circ}$ phosphines $\mathbf{A c}-\mathbf{M a n P H}_{2}$ and $\mathbf{A c}-\mathbf{G l u P H}_{2}$ were purified by column chromatography under $\mathrm{N}_{2}$ with no observable oxidation of the product. Compounds $\mathbf{A c}-\mathbf{M a n P H}_{2}$ and Ac-GluPH ${ }_{2}$ were then dialkylated using 1-hexene to produce tertiary phosphines Ac-ManP and Ac-GluP. Finally, quaternization was achieved using 4-vinylbenzyl chloride to produce the corresponding phosphonium monomers Ac-ManPM and Ac-GluPM ${ }^{M}$. Small scale preparations of Ac-ManPM or AcGluP $^{\mathrm{M}}$ could be easily purified on a deactiviated silica column (details in $\mathrm{SI}$ ) using ethyl acetate-methanol as the mobile phase. Larger scale preparations (e.g. $>0.5 \mathrm{~g}$ ) were purified by oiling out the monomers from dichloromethane with slow addition of hexanes.

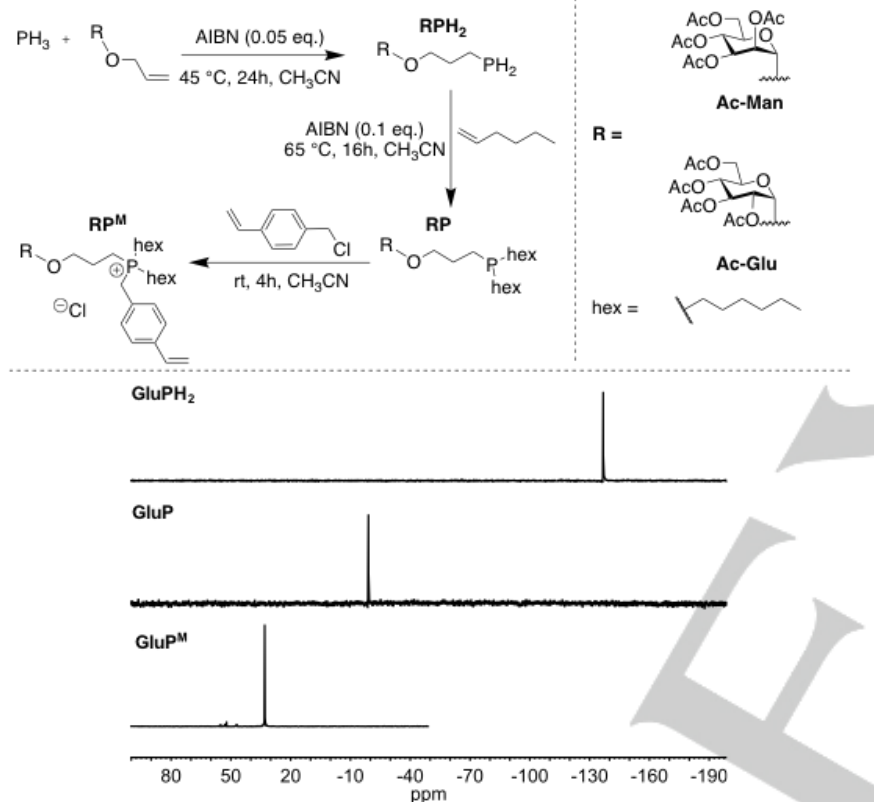

Figure 2. Top: Synthesis of phosphonium monomers from $\mathrm{PH}_{3}(\mathrm{~g})$; Bottom: ${ }^{31} \mathrm{P}\left\{{ }^{1} \mathrm{H}\right\}$ NMR spectra of $1^{\circ}, 3^{\circ}$, and $4^{\circ}$ phosphorus centers with $\mathrm{R}=\mathbf{A c}-\mathbf{G l u}$.

Monomers Ac-ManPM and Ac-GluPM were polymerized by reversible addition fragmentation chain transfer (RAFT) polymerization to obtain the acetate-protected polymers AcManPP and Ac-GluPP respectively (Figure 3). The acetate protecting groups were removed to unmask polymers Man $\mathrm{P}^{\mathrm{P}}$ and GluPP $^{P}$. Two additional control polymers were synthesized via RAFT polymerization from their corresponding phosphonium monomers: poly(tris(hydroxypropyl)vinylbenzylphosphonium chloride) (Hydroxy $\left.\mathrm{P}^{\mathrm{P}}\right)$, and poly(tri(hexyl)vinylbenzyl phosphonium chloride) (HexylPP) (details in SI) (Figure 3). Hydrophilic Hydroxy $P^{P}$ was selected to ascertain the effect of a hydrophilic functional group as compared to the hydrophilic sugar moieties on ManP $P^{P}$ and GluPP, whereas polymer HexyIP ${ }^{P}$ was used to compare to the common polytrialkylphosphonium-based antibacterial polymers. In all cases the degree of polymerization was kept constant at between 30-40 repeat units, as indicated by monomer conversion, based on ${ }^{1} \mathrm{H}$ NMR spectroscopy. Size exclusion chromatography in aqueous and DMF systems was not possible due to column adsorption, but previous work has shown that the polymerization of vinylbenzylphosphonium monomers by RAFT is well controlled. ${ }^{[25]}$

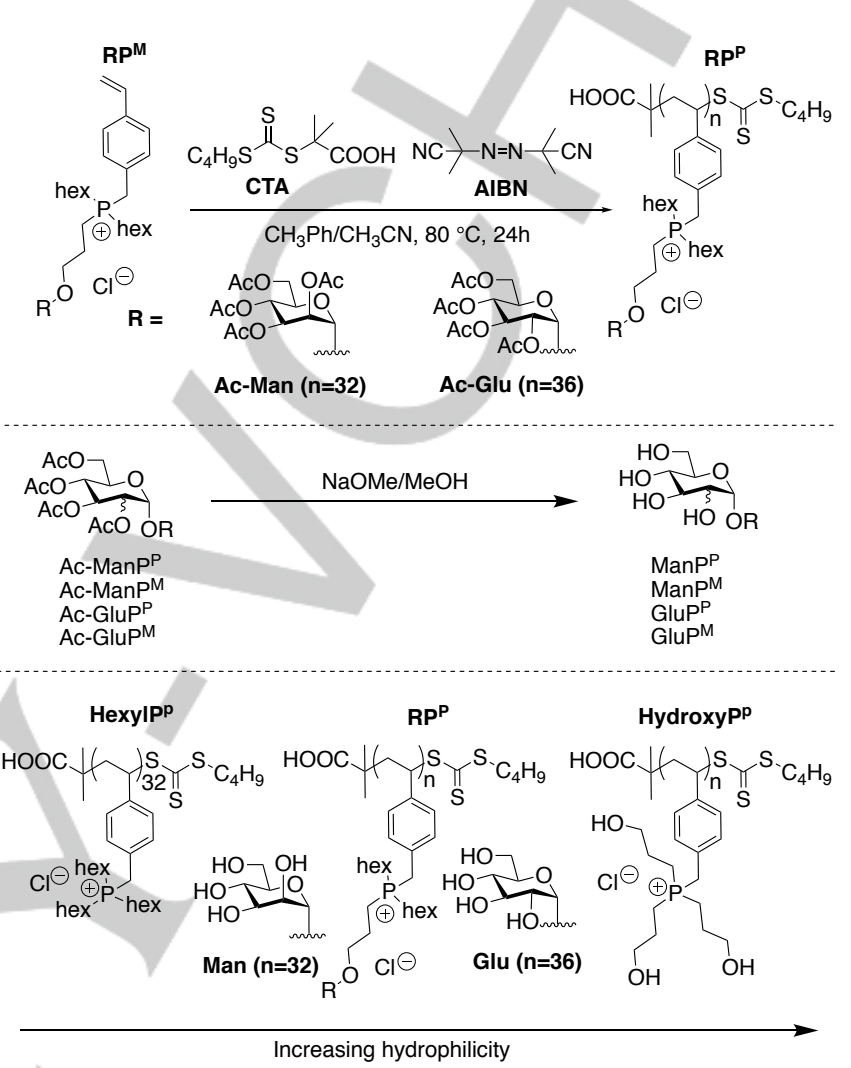

Figure 3. Top: Polymerization of sugar-containing phosphonium monomers to produce polymers Ac-ManP $\mathbf{P}^{\mathrm{p}}$ and Ac-GluPp . Middle: Deprotection of acetateprotected sugars to produce unprotected sugar substituents Man and Glu. Bottom: Structures of polymers tested for antibacterial activity.

The antibacterial activities of the polymers were tested against Gram-negative E. coli (ATCC 29425) and Gram-positive Staphylococcus aureus (S. aureus, ATCC 6538). The polymers were incubated with the bacteria. For concentrations where no growth of the bacteria was observed, the suspensions were plated on agar and the colony forming units (CFUs) were counted after $18 \mathrm{~h}$ to confirm that the bacteria were killed and that these concentrations corresponded to the minimum bactericidal concentration (MBC). Based on the number of bacteria incubated and plated in the assay, these values correspond to a $99.99 \%$ (log 4 reduction) in bacterial CFUs. In addition, to investigate the selectivities of the polymers for bacterial over mammalian cell membranes, their abilities to lyse red blood cells were investigated. The hemolytic concentration $\left(\mathrm{HC}_{50}\right)$ was defined as the concentration at which $50 \%$ of the red blood cells were lysed with respect to positive (100\% lysis) and negative (0\% lysis) controls. The selectivity index was the ratio of the $\mathrm{HC}_{50}$ to the MBC.

Unexpectedly, the mannoside polymer ManP $P^{P}$ had the lowest activity of the polymeric biocides against $E$. coli with an MBC of 
$57 \mu \mathrm{M}$ phosphonium, but had higher activity against $S$. aureus with an MBC of $5.7 \mu \mathrm{M}$ (Table 1, Figure 4). The selectivity indices were 3.1 and 31 against $E$. coli and $S$. aureus respectively. These counterintuitive observations are likely a result of the adhesin for mannose on $E$. coli being located on the end of the pili, away from the cell membrane. Thus, the polymers may have bound to the pili, but were too far from the bacterial membrane to disrupt it. These results contrast with a recent study where star-shaped block copolymers of polylysine and mannose-functionalized polymethacrylates exhibited enhanced microbial targeting and activity relative to those lacking the mannose. ${ }^{[26]}$

Table 1. $\mathrm{MBC}^{[\mathrm{a}]}, \mathrm{HC}_{50}$, and the respective selectivity indices for each polymeric biocide against $E$. coli and $S$. aureus.

\begin{tabular}{|c|c|c|c|c|c|}
\hline Biocide & $\begin{array}{l}\text { E. coli } \\
(\mu \mathrm{M})^{[a]}\end{array}$ & $\begin{array}{l}\text { S. aureus } \\
(\mu \mathrm{M})^{[a]}\end{array}$ & $\begin{array}{l}\mathrm{HC}_{50} \\
(\mu \mathrm{M})\end{array}$ & $\begin{array}{l}\text { E. coli } \\
\text { selectivity } \\
\text { index }\end{array}$ & $\begin{array}{l}\text { S. aureus } \\
\text { selectivity } \\
\text { index }\end{array}$ \\
\hline ManPP & $57 \pm 25$ & $5.7 \pm 2.5$ & 177 & 3.1 & 31 \\
\hline GluPP $^{P}$ & $46 \pm 39$ & 4.3 & 70 & 1.5 & 16 \\
\hline HydroxyPP & 2.7 & 2.7 & $>1060$ & $>390$ & $>390$ \\
\hline HexylPP & 2.3 & $11 \pm 9.9$ & 9.3 & 4.0 & 0.8 \\
\hline ManPM & $92 \pm 128$ & $9.7 \pm 4.2$ & 24 & 0.3 & 2.5 \\
\hline GluPM $^{M}$ & $18 \pm 11$ & 4.9 & 4.9 & 0.3 & 1.0 \\
\hline HydroxyP ${ }^{M}$ & $98 \pm 77$ & $56 \pm 32$ & 472 & 4.8 & 8.5 \\
\hline HexyIP ${ }^{M}$ & 7.5 & $4.6 \pm 2.0$ & 173 & 23 & 38 \\
\hline
\end{tabular}

The antibacterial activity of the glucoside polymer GluPP was similar to that of ManP $P^{P}$, with MBC values of $46 \mu \mathrm{M}$ and $4.3 \mu \mathrm{M}$ against $E$. coli and $S$. aureus respectively. $\sim 2$-Fold lower selectivity indices of 1.5 and 16 for $E$. coli and $S$. aureus respectively were obtained due to this polymer's lower $\mathrm{HC}_{50}$. Both sugar-functionalized polyphosphoniums showed lower activity against Gram-negative E. coli, a trend that has been reported previously for polytrialkylphosphonium biocides. ${ }^{[16]}$ The hydrophilic-lipophilic balance between these two biocides is the same, so targeting capabilities of mannose aside, it is not surprising that they would exhibit the same antibacterial activities. The higher hemolytic activity of GluPP might result from the binding of glucose to glucose transporters on the red blood cell surface. $^{[27]}$

The most lipophilic phosphonium polymer HexyIPP was highly active against $E$. coli with an $\mathrm{MBC}$ of $2.3 \mu \mathrm{M}$, but had a higher MBC of $11 \mu \mathrm{M}$ against $S$. aureus, a trend contradicting that of polymers ManPP and GluPP. It also had a low $\mathrm{HC}_{50}$ value of 9.3 $\mu \mathrm{M}$, leading to low selectivity indices of 4.0 for $E$. coli and 0.8 for $S$. aureus, meaning it is more toxic to red blood cells than $S$. aureus. This reinforces the importance of structural tuning for polymeric phosphonium biocides.

Interestingly, the most hydrophilic polymer HydroxyP $\mathrm{P}^{\mathrm{P}}$, initially intended as a control polymer with pendant hydroxyl groups, had an outstanding MBC value of $2.7 \mu \mathrm{M}$ against both $E$. coli and $S$. aureus. In addition, it showed no hemolytic activity at any tested concentration, providing a very large selectivity index of $>392$ for both $E$. coli and $S$. aureus (Table 1, Figure 4). This is an unprecedented result in the context of the literature on antimicrobial polyonium or related materials. ${ }^{[16,20-22]}$

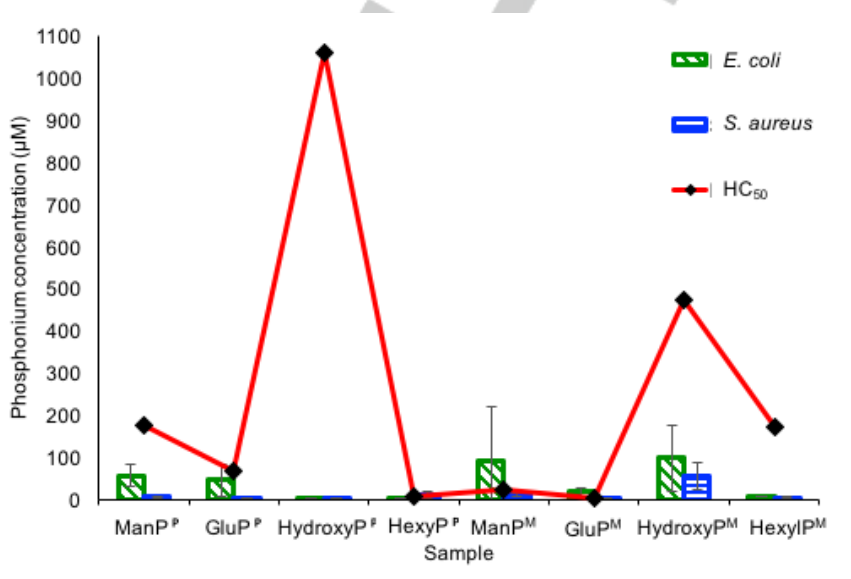

Figure 4. Comparison of $\mathrm{MBC}$ and $\mathrm{HC}_{50}$ values for all samples tested against $E$. coli, S. aureus, and red blood cells.

To understand the role of polyvalency in the activities of these new polymers, the activities of the corresponding monomers were also examined. ${ }^{[16]}$ The deacetylated mannose-functionalized monomer Man $\mathrm{P}^{\mathrm{M}}$ had an $\mathrm{MBC}$ value of $92 \mu \mathrm{M}$ against $E$. coli and a lower MBC value of $9.7 \mu \mathrm{M}$ against $S$. aureus (Table 1, Figure 4). The $\mathrm{HC}_{50}$ was similar at $24 \mu \mathrm{M}$, resulting in low selectivity indices of 0.3 and 2.5 compared to those for the corresponding polymer. The deacetylated glucose-functionalized monomer GluP $^{\mathrm{M}}$ showed higher activity against E. coli (MBC $18 \mu \mathrm{M}$ ) compared to polymer GluPP, while maintaining the same activity against $S$. aureus. However, this monomer displayed high hemolytic activity against red blood cells, leading to low selectivity indices of 1 or lower. Compared to $\mathbf{M a n P}^{\mathrm{M}}$ it had higher activity against all membranes, likely reflecting the differences in the interactions of these carbohydrates with the cell surfaces. The most hydrophilic monomer Hydroxy $\mathrm{P}^{\mathrm{M}}$, had low activity (high $M B C$ values) against both $E$. coli and $S$. aureus, while at the same time having an $\mathrm{HC}_{50}$ value of $472 \mu \mathrm{M}$, lower than that of the corresponding polymer. This resulted in only modest selectivity indices of $4.8 \mu \mathrm{M}$ and $8.5 \mu \mathrm{M}$ respectively for $E$. coli and S. aureus. This demonstrates the importance of the multivalent polymeric form of this phosphonium for the high activity and selectivity of HydroxyP $P^{P}$. Lipophilic monomer HexyIPM, had slightly lower activity compared to the polymeric form HexyIPP, with lower hemolytic activity, resulting in good selectivity of 23.0 (E. coli) and 37.9 (S. aureus), the opposite trend of the hydrophilic monomer.

Overall, the activity of hydrophilic polymer Hydroxy $\mathrm{P}^{\mathrm{P}}$ was the most intriguing result of this work. The assumed requirement for hydrophobic alkyl chains, affording a balance between the hydrophilic and lipophilic components does not seem to apply for this biocide. The substantially lower activity and much higher 
toxicity of its monomeric form Hydroxy $\mathrm{P}^{\mathrm{M}}$, indicates that the polymeric form is critical for this system. It is possible that the hydrophobic polystyrene backbone and even the terminal RAFT group impart amphiphilicity to HydroxyPP so as to enable membrane disruption. Alternatively, it is possible that this polymer exhibits antibacterial properties through an alternative mechanism. Future studies will be directed towards better understanding the mechanism-of-action of Hydroxy $P^{P}$.

We have reported the synthesis, antibacterial activity, and hemolytic concentrations of novel phosphonium-based polymeric biocides. Our initial hypothesis that the mannose-containing phosphonium polymer ManPP $\mathbf{P}^{\mathbf{P}}$ would provide exceptional targeted activity, proved incorrect as it showed lower activity against $E$. coli than $S$. aureus, and similar activity to the glucose-functionalized polyphosphonium GluPP. However, the inclusion of sugars and hydrophilicity increased the $\mathrm{HC}_{50}$ values, resulting in better selectivity values against $S$. aureus in comparison to the most lipophilic conventional biocide, trihexylpolyphosphonium HexyIPP. Including hydroxypropyl substituents on the phosphonium centre increased antibacterial activity and decreased the hemolysis, resulting in very high selectivity for both $E$. coli and $S$. aureus. This intriguing result challenges the hydrophilic-lipophilic balance previously thought required for antibacterial activity.

\section{Experimental Section}

All experimental details are provided in the Supporting Information.

\section{Acknowledgements}

We thank the Natural Sciences and Engineering Research Council of Canada, Ontario Ministry of Research and Innovation and the Canada Foundation for Innovation for research support, Cytec-Solvay for their generous donation tris(hydroxypropyl)phosphine and $\mathrm{PH}_{3(\mathrm{~g})}$.

\section{Conflict of Interest}

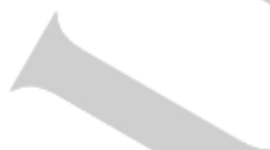

The authors declare no conflict of interest.
Keywords: Antimicrobial activity • Phosphorus - Phosphonium • Phosphine Gas • haemolysis

[1] K. A. Brogden, Nat. Rev. Microbiol. 2005, 3, 238.

[2] M. S. Ganewatta, C. Tang, Polymer 2015, 63, A1.

[3] M. Santos, A. Fonseca, P. Mendonca, R. Branco, A. Serra, P. Morais, J. Coelho, Materials 2016, 9, 599.

[4] L. Timofeeva, N. Kleshcheva, Appl. Microbiol. Biotechnol. 2011 $89,475$.

[5] K. Kuroda, W. F. DeGrado, J. Am. Chem. Soc. 2005, 127, 4128.

[6] A. C. Engler, J. P. K. Tan, Z. Y. Ong, D. J. Coady, V. W. L. Ng, Y. Y. Yang, J. L. Hedrick, Biomacromolecules 2013, 14, 4331.

[7] B. P. Mowery, S. E. Lee, D. A. Kissounko, R. F. Epand, R. M. Epand, B. Weisblum, S. S. Stahl, S. H. Gellman, J. Am. Chem. Soc. 2007, 129, 15474.

[8] V. Sambhy, B. R. Peterson, A. Sen, Angew. Chem. Int. Ed. 2008, 47, 1250.; V. Sambhy, B.R. Peterson, A. Sen, Angew. Chem. 2008, 120,1270

[9] M. F. Ilker, K. Nüsslein, G. N. Tew, E. B. Coughlin, J. Am Chem. Soc. 2004, 126, 15870.

[10] K. Lienkamp, A. E. Madkour, A. Musante, C. F. Nelson, K. Nüsslein, G. N. Tew, J. Am. Chem. Soc. 2008, 130, 9836.

[11] A. C. Engler, N. Wiradharma, Z. Y. Ong, D. J. Coady, J. L. Hedrick, Y. Y. Yang, Nano Today 2012, 7, 201.

[12] Z. M. Al-badri, A. Som, S. Lyon, C. F. Nelson, K. Nusslein, G. N. Tew, Biomacromolecules 2008, 3, 2805.

[13] A. Punia, K. Lee, E. He, S. Mukherjee, A. Mancuso, P. Banerjee, N. L. Yang, Int. J. Mol. Sci. 2015, 16, 23867.

[14] D. Fischer, Y. Li, B. Ahlemeyer, J. Krieglstein, T. Kissel, Biomaterials 2003, 24, 1121.

[15] K. A. Gibney, I. Sovadinova, A. I. Lopez, M. Urban, Z. Ridgway, G. A. Caputo, K. Kuroda, Macromol. Biosci. 2012, 12, 1279.

[16] A. Kanazawa, T. Ikeda, T. Endo, J. Polym. Sci. Part A Polym. Chem. 1993, 31, 335.

[17] T. Cuthbert, R. Guterman, P. J. Ragogna, E. R. Gillies, J. Mater. Chem. B 2015, 3, 1474.

[18] T. J. Cuthbert, T. D. Harrison, P. J. Ragogna, E. R. Gillies, J. Mater. Chem. B 2016, 4, 4872.

[19] A. Kanazawa, T. Ikeda, T. Endo, J. Polym. Sci. Part A Polym. Chem. 1993, 31, 1441.

[20] A. Kanazawa, T. Ikeda, T. Endo, J. Appl. Polym. Sci. 1994, 53, 1237.

[21] A. Kanazawa, T. Ikeda, T. Endo, J. Polym. Sci. Part A Polym. Chem. 1994, 32, 1997.

[22] A. Kanazawa, T. Ikeda, T. Endo, Antimicrob. Agents Chemother. 1994, 38, 945

[23] T. Anthierens, L. Billiet, F. Devlieghere, F. Du Prez, Innov. Food Sci. Emerg. Technol. 2012, 15, 81.

[24] J. Bouckaert, J. Berglund, M. Schembri, E. De Genst, L. Cools, M. Wuhrer, C. S. Hung, J. Pinkner, R. Slättegård, A. Zavialov, et al., Mol. Microbiol. 2005, 55, 441.

[25] G. Moad, E. Rizzardo, S. H. Thang, Aust. J. Chem. 2005, 58, 379.

[26] D. Pranantyo, L. Q. Xu, Z. Hou, E. T. Kang, M. B. Chan-Park, Polym. Chem. 2017, 8, 3364.

[27] M. Mueckler, C. Caruso, S. A. Baldwin, M. Panico, I. Blench, H. R. Morris, J. W. Allard, G. E. Lienhard, H. F. Lodish, Science 1985, 229,941 . 
Entry for the Table of Contents (Please choose one layout)

Layout 1:

\section{COMMUNICATION}

Deadly sweet! "Bait and kill" strategies using phosphonium-based polymers appended with hydrophilic groups such as sugars or hydroxyl and employed as highly effective antibacterial agents with minimal haemolysis of red blood cells. This challenges the conventional wisdom that hydrophobic appendages on biocides are necessary.

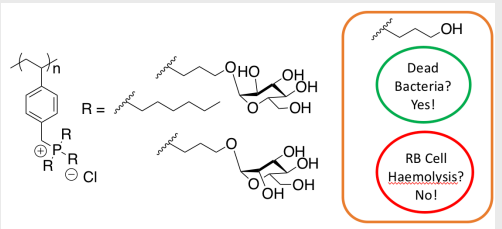

Tyler J. Cuthbert, ${ }^{[a]}$ Benjamin Hisey, ${ }^{[a]}$ Tristan D. Harrison, ${ }^{[a]}$ John F. Trant, ${ }^{[a]}$, Elizabeth R. Gillies, ${ }^{*[a][b]}$ and Paul J. Ragogna ${ }^{*[a]}$ Page No. - Page No.

Surprising Antibacterial Activity and Selectivity of Hydrophilic

Polyphosphoniums Featuring Sugar and Hydroxyl Substituents 